\title{
PENGARUH CASH RATIO, TIME INTEREST EARNED DAN DEBT TO EQUITY RATIO TERHADAP PROFITABILITAS (ROE) PADA PERUSAHAAN PERBANKAN YANG TERDAFTAR DALAM BEI PERIODE 2013-2017
}

\author{
Angellia $^{1}$, Erlina ${ }^{2}$, Jana Jesifa Moksa ${ }^{3}$, Joshua Andre Wirawan ${ }^{4}$, Novilia Wijaya ${ }^{5}$ \\ Jessy Safitri Sitorus ${ }^{6}$, Andhy Stephanus ${ }^{7}$ \\ 1,2,3,4,5,6,7 Prodi Akuntansi, Fakultas Ekonomi, Universitas Prima Indonesia, Jalan Belanga No. 1 Simp. Ayahanda, \\ Medan, Sumatera Utara, 20118, Indonesia \\ E-mail: angelliachen@yahoo.com
}

\begin{abstract}
Financial performance can be measured by Return on Equity (ROE), because ROE is one of two base factors to determine company's level of profit growth. A company can be identified success if the cash turnover is increasing along the certain financial period. If liquidity is increasing then the profit will increase because the changed value of current assets is getting increased by company's current liabilities enchancement. The sample of research is 32( thirthy two companies ) Data collection method is using documentation method Data analysis thechnique used is descriptive quantitative analysis. Analysis model in this research is double linear regretion and using SPSS program. Data tested by classic assumption test, coefficient determination test, $F$ test, and $T$ test. The conclusion of this research both partial and simultaneous Cash Ratio ,Time Interest Earned, Debt to Equity Ratio are not influential to Return on Equity. The result of $R$ coeffition determination is 7,3\%. So this 7,3\% variation of variable ROE can be explained by variation variable Cash Ratio, Time Interest Earned, Debt to Equity Ratio
\end{abstract}

Keywords: ROE, Cash Ratio, Time Interest Earned, Debt to Equity Ratio.

\section{PENDAHULUAN}

Sumber utama permodalan eksternal bagi perusahaan dan pemerintah dalam pembelian dan penjualan adalah bursa efek atau pasar uang yang berada dalam sebuah tempat pusat, yang digunakan untuk mengcatat, tetapi dalam masa modern seperti sekarang lebih banyak menggunakan sistem elektronik yang lebih cepat dan lebih mudah. Publik dapat melihat dan memperoleh informasi yang lebih lengkap tentang perkembangan bursa saham melalui Bursa Efek Indonesia yang mulai beroperasional pada tanggal 1 Desember 2007.Bagi perekonomian suatu negara Bursa Efek Indonesia memberikan peran yang besar karena memberikan dua fungsi sekaligus, fungsi ekonomi dan fungsi keuangan yang memberikan kesempatan memperoleh return bagi para investor

Salah satu tempat utama yang digunakan masyarakat untuk menyimpan uang, menyalurkan uang, dan melakukan jasa lainnya yang berhubungan dengan uang adalah sektor perbankan atau yang biasa kita sebut bank yang berperan sebagai perantara keuangan (financial intermediary). Peran utama bank adalah menjaga kepercayaan nasabah dan menjamin tingkat likuiditas dapat beroperasi secara efektif dan efisien untuk mencapai profitabilitas yang tinggi sebagai penggerak utama pertumbuhan ekonomi di Indonesia. Laba bank itu sendiri dapat diukur melalui rasio profitabilitas yang dapat mengetahui kemampuan perusahaan dalam menghasilkan laba selama periode tertentu dan juga memberikan gambaran tentang tingkat efektifitas manajemen dalam melaksanakan kegiatan operasinya. Hal ini dapat dilihat dari laba yang dihasilkan terhadap penjualan dan investasi perusahaan. Salah satu rasio profitabiltas yang dapat digunakan untuk mengukur laba perusahaan adalah Return on 
Equity dalam mengukur efekivitas perusahaan didalam menghasilkan keuntungan dengan memanfaatkan ekuitas yang dimilkinya. Cash Ratio untuk melihat kewajiban lancarnya dengan membandingkan total kas tunai dan setara kas perusahaan yang digunakan untuk mengetahui apakah perusahaan dapat membayar hutang jangka pendeknya. Rasio kas paling ketat dan konservatif terhadap kemampuan perusahaan dalam menutupi hutang atau kewajiban jangka pendeknya dikarenakan rasio kas hanya memperhitungkan aset atau aktiva lancar jangka pendek yang paling likuid yaitu kas dan setara kas yang paling mudah dan cepat untuk digunakan dalam melunasi hutang lancarnya. Times Interest Earned Ratio menunjukkan besarnya jaminan keuntungan untuk membayar bunga hutang jangka panjang. Times Interest Earned biasa digunakan untuk membayar bunga dan utangnya dengan kata lain perusahaan harus memiliki EBIT banyak agar dapat membayar beban bunganya. Debt to Equity Ratio (DER) di jadikan acuan dalam mengukur dan menganalisis laporan keuangan untuk memperlihatkan besarnya jaminan yang tersedia untuk kreditor.

\section{TINJAUAN PUSTAKA}

Cash Ratio. Cash rasio yang digunakan untuk menilai besar uang kas yang digunakan untuk membayar utang jangka pendek (Hery, 2015). Rasio kas adalah sebagai alat untuk melihat berapa banyaknya uang kas yang ada untuk perusahaan untuk mencukupi atau membayar kewajiban utang lancar dengan aset lancar dengan tidak memperhitungkan nilai sediaan (Kasmir, 2012). Cash rasio melihat kemampuan perusahaan membayar utang lancarnya dengan dana perusahaan atau yang setara dengan kas (Sawir,2015).

$$
\text { Rasio Kas }=\frac{\text { Kas dan setara kas }}{\text { Kewajiban lancar }}
$$

Time Interest Earned. Time Interest Earned adalah rasio yang mengukur sejauh mana atau berapa kali kemampuan perusahaan dalam membayar bunga (Hery,2015). Menurut Sawir (2015) mengatakan bahwa Time Interest Earned melihat kemampuan pemenuhan kewajiban bunga tahunan dengan laba operasi (EBIT)

$$
\text { Time Interest Earned }=\frac{\text { EBIT }}{\text { Biaya Bunga }}
$$

Debt To Equity Ratio. Debt to Equity Ratio adalah rasio untuk menghitung utang dengan modal (Kasmir 2014). Debt to Equity Ratio memaparkan hubungan antara total pinjaman jangka panjang dengan total modal sendiri (Syamsuddin, 2011)

$$
\text { Debt to Equity Ratio }=\frac{\text { Total Utang }(\text { Debt })}{\text { Ekuitas }(\text { Equity) }}
$$

Return on Equity. Return on equity adalah pengukuran dari penghasilan yang ada untuk para pemegang saham atas modal yang mereka investasikan di dalam perusahaan (Syamsuddin, 2011). Hasil pengembalikan ekuitas (Return on Equity) adalah rasio untuk melihat laba bersih dengan modal sendiri (Kasmir, 2012). Return on equity melihat kemampuan perusahaan mendapatkan laba bagi para pemegang saham perusahaan (Sartono, 2010)

$$
\text { Return On Equity }(\mathrm{ROE})=\frac{\text { Earning After Interest and Tax }}{\text { Equity }}
$$


Cash Ratio Terhadap Profitabilitas (ROE). Jika likuiditas mengalami peningkatan maka profit akan mengalami peningkatan dikarenakan berubahnya nilai aset lancar yang terus meningkat disertai peningkatan hutang lancar perusahaan (Kusriyanti, 2017). Perusahaan yang likuiditasnya terlalu tinggi juga kurang bagus, karena banyaknya dana menganggur yang pada akhirnya dapat mengurangi kemampuan labaan perusahaan. (Sawir, 2015)

$\mathbf{H}_{1}$. Cash Ratio memiliki pengaruh pada Return on Equity

Time Interest Earned Terhadap Profitabilitas (ROE). Kemampuan perusahaan dalam membayar seluruh hutangnya dapat dilihat melalui rasio TIER. Profitabilitas perusahaan yang meningkat menunjukkan TIER yang baik (Avistasari dkk 2016). Penggunaan financial leverage dapat memberikan pengaruh positif berupa profitabilitas yang meningkat dalam kondisi ekonomi yang baik. Dikarenakan tingkat pengembalian terhadap laba operasi perusahaan cukup untuk membelanjakan hutang yang banyak karena laba yang didapat masih dapat digunakan untuk mengurangi beban tetap yang muncul akibat penggunaan hutang itu (Ritonga dkk 2014),

H. Time Interest Earned memiliki pengaruh pada Return on Equity

Debt to Equity Ratio Terhadap Profitabilitas (ROE). Rasio Leverage menunjukkan hubungan antara utang perusahaan terhadap modal aset. Debt to Equity Ratio adalah perbandingan antara total utang yang dimiliki perusahaan dengan modal sendiri Debt to Equity Ratio digunakan perusahaan untuk melihat seberapa besar ekuitas yang dimiliki untuk menjamin utangnya. Semakin banyak Debt to Equity Ratio menunjukan semakin banyak biaya hutang yang harus dibayar perusahaan sehingga profitabilitas berkurang (Harahap, 2015). Salah satu faktor yang mempengaruhi Debt to Equity Ratio adalah Profitabilitas. Profitabilitas periode sebelumnya merupakan faktor penting dalam menentukan struktur modal (Sartono, 2010)

$\mathbf{H}_{3}$. Debt to equity Ratio memiliki pengaruh pada Return on Equity

\section{METODE PENELITIAN}

Jenis Penelitian. Jenis penelitian ini menggunakan pendekatan kuantitatif, bertujuan untuk meneliti populasi atau sampel tertentu. Sifat penelitian adalah hubungan sebab akibat yaitu untuk mengetahui pengaruh variabel bebas Cash Ratio $\left(\mathrm{X}_{1}\right)$, Time Interest Earned $\left(\mathrm{X}_{2}\right)$, dan Debt to Equity Ratio $\left(\mathrm{X}_{3}\right)$ terhadap Profitabilitas (ROE) baik secara parsial maupun simultan. Data yang dipakai adalah yang bersifat sekunder berupa financial report pada perusahaan perbankan yang berturut-turut dalam BEI periode 2013-2017.

Sampel dan teknik pengambilan sampel. Populasi penelitian ini adalah perusahaan perbankan yang terdaftar di BEI tahun 2013-2017 dengan jumlah total 43 perusahaan. Teknik pengambilan sampel dengan menggunakan purposive sampling jumlah sampel yang didapatkan yaitu 32 perusahaan dan dikalikan dengan tahun penelitian maka didapatkan 160 data penelitan. Kriteria untuk pemilihan sampel pemilihan ini adalah:

1. Perusahaan perbankan yang terdaftar dalam BEI periode 2013 - 2017.

2. Perusahaan tersebut mempublikasikan financial report yang telah diaudit lengkap secara berturut-turut periode 2013 - 2017.

3. Perusahaan tersebut menghasilkan laba positif periode 2013 - 2017.

Metode Analisis. Metode penelitian yang digunakan adalah analisis kuantitatif, metode dalam penelitian ini adalah model regresi linier berganda melalui aplikasi Statistical Package for Social Science (SPSS). 


\section{HASIL ANALISIS DAN PEMBAHASAN}

\subsection{Hasil analisis}

Pengujian Asumsi Klasik untuk mengetahui benar atau salah suatu regresi yang dipakai dalam penelitian. Uji persyaratan analisis ini ada 4 yaitu pengujian normalitas, multikolinearitas, autokorelasi, dan heteroskedastisitas

a. Pengujian Normalitas ini digunakan untuk mengetahui apakah dalam sebuah model regresi, nilai residu dari regresi mempunyai distribusi yang normal. Suatu model layak digunakan jika mempunyai variabel bebas dan terikat yang mendekati normal atau berdistribusi normal dalam pengujian normalitas penelitian ini menggunakan uji statistik non-parametik Kolmogorov Smirnov (K-S).

Tabel 1.Pengujian Normalitas

\begin{tabular}{lll}
\hline & & \multicolumn{1}{c}{$\begin{array}{c}\text { Unstandardized } \\
\text { Residual }\end{array}$} \\
\hline $\mathrm{N}$ & & 135 \\
Normal Parameters $^{\mathrm{a}}$ & Mean & 0,0000000 \\
& Std. Deviation & 0,26882702 \\
& Absolute & 0,096 \\
Most Extreme Differences & Positive & 0,096 \\
& Negative & $-0,081$ \\
Kolmogorov-Smirnov Z & & 1,119 \\
Asymp. Sig. (2-tailed) & & 0,163 \\
\hline
\end{tabular}

Tabel 1 dapat dilihat nilai Kolmogorov-Smirnov sebesar 1,119 dan nilai Asymp.Sig. (2tailed) 0,163>0,05 sehingga model memiliki residual yang berdistribusi normal.

b. Pengujian Multikolinearitas ini digunakan untuk meneliti apakah pada model regresi ditemukan adanya korelasi/keterkaitan antar-variabel bebas. Model regresi yang baik adalah tidak terjadi korelasi diantara variabel bebas. Untuk mendeteksi ada atau tidak adanya multikolinieritas di dalam model regresi adalah nilai tolerance dan VIF (Value-Inflating Factor), dengan nilai tolerance $\leq$ 0,10 dan dengan nilai VIF $\geq 10$.

Tabel 2. Pengujian Multikolinieritas

\begin{tabular}{lcrr}
\hline \multirow{2}{*}{ Model } & \multicolumn{2}{c}{ Collinearity Statistics } \\
\cline { 2 - 4 } \multicolumn{1}{c}{1} & Ln_CashRatio & 0,959 & VIF \\
& Ln_TIER & 0,868 & 1,043 \\
& Ln_DER & 0,895 & 1,153 \\
\multicolumn{1}{l}{ a. Dependent Variable: Ln_ROE } & & 1,118 \\
\hline
\end{tabular}

Berdasarkan hasil uji multikolinieritas pada tabel 2 diketahui bahwa nilai tolerance value semua variabel independen berada di atas 0,10 yaitu sebesar 0,959 untuk cash ratio sebagai $\mathrm{X}_{1}, 0,868$ untuk TIER sebagai $\mathrm{X}_{2}$ dan 0,895 untuk DER sebagai $\mathrm{X}_{3}$. Sedangkan nilai variance inflation factor (VIF) antara variabel $\mathrm{X}_{1}$ cash ratio adalah 1,043, $\mathrm{X}_{2}$ TIER adalah 1,153 dan $\mathrm{X}_{3}$ DER adalah 1.118 berada di bawah 10. Jadi dapat disimpulkan bahwa penelitian ini berdasarkan nilai Tolerance dan VIF tidak terjadi multikolinearitas. 
c. Pengujian Autokorelasi ini dilakukan mengetahui dalam sebuah model regresi linier ada kaitannya antara kesalahan pengganggu pada periode pada tiap variabel independen yang saling berkaitan.

Tabel 3. Pengujian Autokorelasi

\begin{tabular}{cc}
\hline Model & Durbin-Watson \\
\hline 1 & 1,401 \\
\hline
\end{tabular}

a. Predictors: (Constant), Ln_DER, Ln_CashRatio, Ln_TIER

b. Dependent Variable: Ln_ROE

Tabel 3 menunjukkan hasil uji autokorelasi dengan menggunakan uji durbin watson adalah 1,401, sedangkan nilai $\mathrm{dl}=1,6738 \mathrm{dan} \mathrm{du}=1,7645$, keputusan dalam penelitian ini dapat disimpulkan tidak terjadi autokorelasi

d. Pengujian Heteroskedastisitas pengujian dilakukan untuk melihat dalam sebuah model regresi, terjadi perbedaan varians residual dari satu pengamatan dengan pengamatan yang lain. Jika varians residual dari satu pengamatan dengan pengamatan yang lain tetap, maka hal itu dikatakan homoskedastisitas.

Scatterplot

Dependent Variable: Ln_ROE

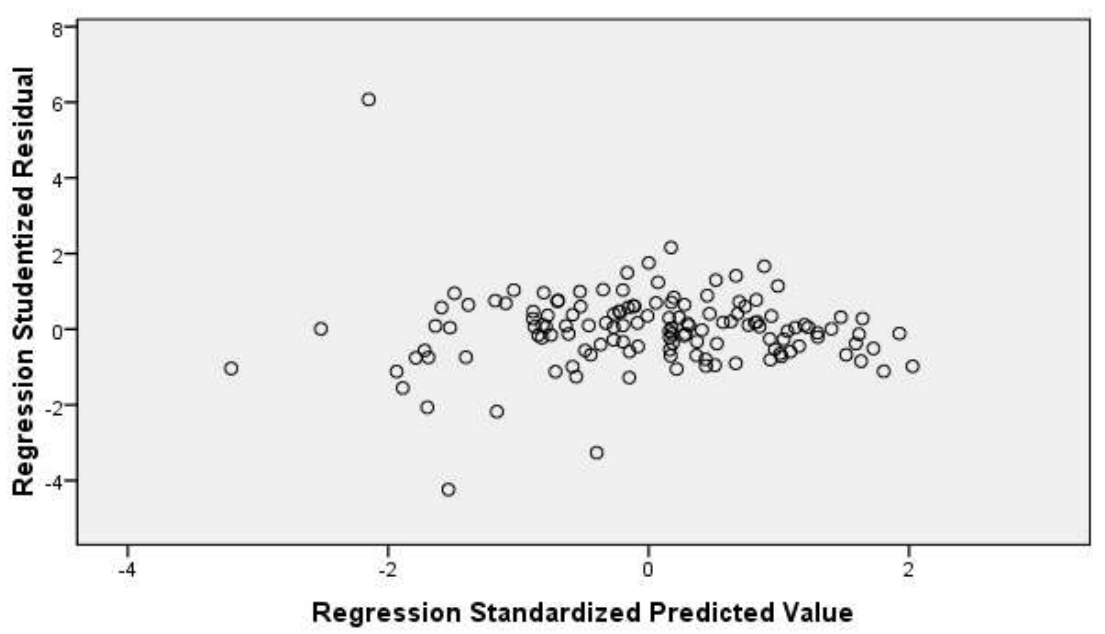

Gambar 1. Pengujian Heteroskedastisitas

Berdasarkan gambar 1 dapat dilihat bahwa titik-titik menyebar secara acak dan menyebar diatas dan dibawah angka 0 pada sumbu Y. Hal ini dikatakan bahwa data penelitian tidak mengalami heteroskedastisitas. 
Pengujian Linier Berganda. Tabel 4 menunjukkan hasil dari linier berganda

Tabel 4. Hasil PengujianLinier Berganda

\begin{tabular}{|c|c|c|c|c|c|c|}
\hline & \multirow[b]{2}{*}{ Model } & \multicolumn{2}{|c|}{$\begin{array}{c}\text { Unstandardized } \\
\text { Coefficients } \\
\end{array}$} & \multirow{2}{*}{$\begin{array}{c}\begin{array}{c}\text { Standardized } \\
\text { Coefficients }\end{array} \\
\text { Beta } \\
\end{array}$} & \multirow[b]{2}{*}{$\mathbf{t}$} & \multirow[b]{2}{*}{ Sig. } \\
\hline & & B & Std. Error & & & \\
\hline \multirow[t]{4}{*}{1} & (Constant) & $-3,587$ & 0,119 & & $-30,139$ & 0,000 \\
\hline & Ln_CashRatio & 0,020 & 0,014 & 0,049 & 1,452 & 0,149 \\
\hline & Ln_TIER & 0,687 & 0,026 & 0,956 & 26,781 & 0,000 \\
\hline & Ln_DER & 0,968 & 0,067 & 0,510 & 14,520 & 0,000 \\
\hline
\end{tabular}

a. Dependent Variable: Ln_ROE

$$
\text { LnROE }=-3,587+0,020 \text { LnCash Ratio + 0,687 LnTIER + 0,968 LnDER }
$$

Berdasarkan tabel 4 dapat dijelaskan hasil pengujian ini adalah :

1. Dari hasil pengolahan data untuk menguji pengaruh variabel bebas secara parsial adalah nilai $\mathrm{t}_{\text {hitung }}$ cash ratiosebesar 1,452 , nilai Sig. 0,149 maka $\mathrm{t}_{\text {hitung }} \square \mathrm{t}_{\text {tabel }}(1,452 \square$ 1,97824) yang berarti bahwa cash ratio tidak berpengaruh terhadap ROE pada perusahaan perbankan terdaftar dalam BEI periode 2013-2017.

2. Dari hasil pengolahan data untuk menguji pengaruh variabel bebas secara parsial adalah nilai $t_{\text {hitung }}$ TIER sebesar 26,781, nilai Sig. 0,000 maka $t_{\text {hitung }} \square \mathrm{t}$ tabel $(26,781$ $\square 1,97824$ ) yang berarti bahwa TIER berpengaruh positif signifikan terhadap ROE pada perusahaan perbankan terdaftar dalam BEI periode 2013-2017.

3. Dari hasil pengolahan data untuk menguji pengaruh variabel bebas secara parsial nilai $\mathrm{t}_{\text {hitung }}$ debt to equity ratio sebesar 14,520 , nilai Sig. $0,000 \mathrm{t}$ hitung $\square \mathrm{t}$ tabel $(14,520$ $\square 1,97824)$ yang berarti bahwa debt to equity ratio berpengaruh positif signifikan terhadap ROE pada perusahaan perbankan terdaftar dalam BEI periode 2013-2017.

Berdasarkan tabel 5 didapatkan hasil nilai $F_{\text {hitung }}$ sebesar 257,798 dengan probabilitas 0,000 . Pada derajat bebas $1\left(\mathrm{df}_{1}\right)=\mathrm{k}-1=4-1=3$, dan derajat bebas $2\left(\mathrm{df}_{2}\right)=\mathrm{n}-\mathrm{k}-1=135-3-1$ $=131$, dimana $\mathrm{n}=$ jumlah sampel, $\mathrm{k}=$ jumlah variabel. Nilai $\mathrm{F}_{\text {tabel }}$ pada taraf kepercayaan signifikansi 0,05 adalah 2,67 karena probabilitas jauh lebih kecil dari 0,05 dan nilai $\mathrm{F}_{\text {hitung }}$ lebih besar dari nilai $F_{\text {tabel }}$, maka dari data setelah transformasi, model regresi dapat digunakan untuk memprediksi Cash ratio, TIER dan Debt To Equity Ratio secara bersama-sama berpengaruh terhadap ROE.

Tabel 5.Pengujian Simultan

\begin{tabular}{llrrrrr}
\hline & Model & Sum of Squares & df & Mean Square & F & Sig. \\
\hline 1 & Regression & 57,172 & 3 & 19,057 & 257,798 & $0,000^{\mathrm{a}}$ \\
& Residual & 9,684 & 131 & 0,074 & & \\
& Total & 66,856 & 134 & & & \\
\hline
\end{tabular}

a. Predictors: (Constant), Ln_DER, Ln_CashRatio, Ln_TIER

b. Dependent Variable: Ln_ROE 


\subsection{Pembahasan}

Pengaruh Cash Ratio Terhadap ROE. Dari hasil pengujian hipotesis secara statistik diperoleh hasil dengan $t_{\text {hitung }} \square \mathrm{t}$ tabel $(1,452 \square$ 1,97824) dengan nilai signifikansi $0,149 \square 0,05$ yang berarti bahwa cash ratio tidak berpengaruh terhadap ROE pada perusahaan perbankan terdaftar dalam BEI periode 2013-2017. Penelitian ini tidak sejalan dengan penelitian yang dilakukan oleh Enggarwati dan Yahya (2016) dengan judul "Pengaruh Leverage Dan Likuiditas Terhadap Profitabilitas Pada Perusahaan Otomotif Di BEI" yang menyatakan bahwa cash ratio memiliki pengaruh negatif signifikan terhadap profitabilitas.

Pengaruh Times Interest Earned Terhadap ROE. Hasil pengujian hipotesis secara parsial (Uji-t) diperoleh hasil dengan nilai t hitung $\square \mathrm{t}$ tabel $(26,781 \square$ 1,97824) dengan nilai signifikansi $0,000<0,05$ yang berarti bahwa TIER memiliki pengaruh positif signifikan terhadap ROE pada perusahaan perbankan yang terdaftar dalam BEI periode 2013-2017.Penelitian ini sejalan dengan teori Avitasari, dkk (2016) Rasio TIER menunjukkan kemampuan perusahaan dalam menutupi semua beban utangnya. Maka perusahaan yang mempunyai tingkat TIER yang baik akan meningkatkan profitabillitas perusahaan.

Pengaruh Debt to Equity Ratio Terhadap ROE. Menunjukkan hasil pengujian hipotesis secara parsial (Uji-t) dengan data setelah transformasi diperoleh hasil dengan nilai t hitung $\square \mathrm{t}$ tabel $(14,520 \square$ 1,97824) dengan nilai signifikansi $0,000 \square \quad 0,05$ yang berarti bahwa Debt to Equity Ratio berpengaruh positif signifikan pada ROE pada perusahaan perbankan yang terdaftar dalam BEI periode 2013-2017. Penelitian ini sejalan dengan penelitian Hantono (2015) dengan judul Pengaruh Current Ratio Dan Debt To Equity Ratio Terhadap Profitabilitas Pada Perusahaan Manufaktur Sektor Logam Dan Sejenisnya Yang Terdaftar Di Bursa Efek Indonesia Periode 2009 -2013 yang menyatakan Debt to Equity Ratio berpengaruh terhadap Return on Equity

\section{KESIMPULAN DAN SARAN}

\subsection{Kesimpulan}

Kesimpulan dari hasil penelitian ini secara parsial Cash Ratio tidak berpengaruh terhadap ROE, Time Interest Earned berpengaruh positif terhadap ROE, Debt to Equity Ratio berpengaruh positif terhadap ROE. dan pengujian simultan Cash Ratio, Time Interest Earned dan Debt to Equity Ratio secara bersama-sama berpengaruh terhadap ROE.

\subsection{Saran}

Saran-saran yang dapat diberikan oleh peneliti adalah sebagai berikut:

1. Bagi perusahaan khususnya pihak manajemen disarankan untuk dapat mengelola modal kerja dengan baik agar dapat meminimalkan pengeluaran biaya-biaya dan memaksimalkan perolehan ROEnya. Selain itu pihak manajemen perlu untuk mempertahankan nilai atau tingkat penjualan agar tujuan perusahaan untuk memaksimalkan laba dapat tercapai. Hal ini dikarenakan dalam penelitian ini membuktikan bahwa Cash ratio, TIER dan DER secara bersama-sama berpengaruh terhadap ROE

2. Bagi calon investor disarankan untuk mencari informasi mengenai profil perusahaan terlebih dahulu agar dapat mengetahui kinerja perusahaan sebelum melakukan investasi.

3. Bagi peneliti selanjutnya yang tertarik untuk melakukan penelitian lebih lanjut, disarankan untuk dapat mengambil sampel perusahan yang bergerak dalam sektor lain contohnya : properti atau perikanan agar dapat menambahkan variabel bebas (independen) yang lain seperti harga pokok Perputaran Kas, biaya produksi dan lain-lain. 
4. Bagi Universitas Prima Indonesia, khususnya para pembaca pustaka disarankan untuk dapat mencari lebih banyak referensi penelitian dan membandingkan dengan hasil penelitian yang lainnya

\section{DAFTAR PUSTAKA}

Adare,dkk. 2015. Pengaruh Likuiditas Bank Terhadap Return on Asset Pada Bank Swasta Nasional Yang Terdaftar Di Bursa Efek Indonesia Periode 2008-2013. Jurnal Berkala Ilmiah Efisiensi Volume 15 No. 05 Tahun 2015

Ashari, Muhammad Hajar. R. Djoko Sampurno. 2017. Pengaruh Leverage Keuangan Terhadap Profitabilitas Pada Perusahaan Pariwisata Yang Terdaftar Di Bursa Efek Indonesia Periode 2011-2015. DIPONEGORO JOURNAL OF MANAGEMENT http://ejournal s1.undip.ac.id/index.php/dbr Volume 6, Nomor 4. Tahun 2017, Halaman 1-12 ISSN (Online): 2337-3792

Avistasari, Fieka Kurnia. Topowijono. Zahroh ZA. 2016. Pengaruh Financial Leverage Terhadap Profitabilitas Perusahaan (Studi pada Perusahaan Manufaktur Sektor Aneka Industri Sub Sektor Otomotif dan Komponen yang Terdaftar di BEI Periode 20122014). Jurnal Administrasi Bisnis (JAB)|Vol. 32 No. 1 Maret 2016

Brigham, Houston.2012. Dasar-Dasar Manajemen Keuangan. Salemba Empat

Ghozali, Imam. 2013. Aplikasi Analisis Multivariate Dengan Program IBM SPSS 21. Ed. 7, Semarang : Badan Penerbit Universitas Diponegoro.

Hantono. 2015. Pengaruh Current Ratio Dan Debt to Equity Ratio Terhadap Profitabilitas Pada Perusahaan Manufaktur Sektor Logam Dan Sejenisnya Yang Terdaftar Di Bursa Efek Indonesia Periode 2009 -2013. Jurnal Wira Ekonomi Mikroskil Vol 5, Nomor 01, April 2015

Harahap, Sofyan Syafri.2015. Analisis Kritis Laporan Keuangan. Jakarta: PT. Raja Grafindo Persada

Hery. 2015. Analisis Laporan Keuangan Pendekatan Rasio Keuangan. Yogyakarta: CAPS

Kasmir. 2012. Analisis Laporan Keuangan. Jakarta : PT Rajagrafindo Persada.

Kasmir.2014. Manajemen Perbankan. PT Rajagrafindo Persada.

Kusriyanti, Iyus. 2017. Analisis Pengaruh Current Ratio (CR), Debt Ratio (DR), dan Total Asset Turnover (TATO) Terhadap Profitabilitas (ROI) Perusahaan Telekomunikasi Di Indonesia (Studi Kasus Pada Perusahaan Telekomunikasi Yang Terdaftar Di Bursa Efek Indonesia Tahun 2009-2016). Universitas PGRI Yogyakarta.

Munawir. 2014. Analisa Laporan Keuangan. Cetakan Keempat Belas. Yogyakarta: Liberty Yogyakarta.

Ritonga, Maharani. Kertahadi. Sri Mangesti Rahayu. 2014. Pengaruh Financial Leverage Terhadap Profitabilitas (Studi pada Perusahaan Makanan dan Minuman yang Terdaftar pada Bursa Efek Indonesia Periode Tahun 2010-2012). Jurnal Administrasi Bisnis (JAB) | Vol. 8 No. 2 Maret 2014

Riyanto, Bambang. 2009. Dasar dasar Pembelanjaan Perusahaan. Cetakan Keenam. Yogyakarta : BPFE

Sanusi, Anwar. 2017. Metodologi Penelitian Bisnis. Cetakan Keempat. Jakarta: Salemba Empat.

Sartono, Agus. 2010. Manajemen Keuangan, Teori dan Aplikasi. Ed 4. Yogyakarta: BPFE

Sawir, Agnes. 2015. Analisis Kinerja Keuangan Dan Perencanaan Perusahaan. Cetakan Kesepuluh. Jakarta: PT. Gramedia Pustaka Utama.

Silaen, Sakti. 2010. Statistika Untuk Bisnis dan Ekonomi. Ed.Pertama. Jakarta: Mitra Wacana Media 
Sudana, I Made. 2011. Manajemen Keuangan Perusahaan Teori \& Praktik. PT. Gelora Aksara Pratama

Sugiyono. 2012. Metode Penelitian Bisnis. Bandung: Alfabeta

Syamsuddin, Lukman. 2011. Manajemen Keuangan Perusahaan . Cetakan Kesebelas. Jakarta: PT. Raja Grafindo Persada.

Zulganef. 2013. Metode Penelitian Sosial dan Bisnis. Cetakan kedua. Yogyakarta; Graha Ilmu 